\title{
ANALISA KEBUTUHAN AIR BAKU BERDASARKAN MATA AIR SUNGAI BAYONG ( Study Kasus di Kec. Bendungan Kab. Trenggalek )
}

\author{
Oky Ari Swenda *1, Ahmad Ridwan ${ }^{2}$, Sigit Winarto ${ }^{3}$. \\ ${ }^{1,2,3}$ Fakultas Teknik, Universitas Kadiri. \\ e-mail:*1 oariswenda@gmail.com, 2ahmad_ridwan@unik-kediri.ac.id, \\ 3 sigit.winarto@unik-kediri.ac.id.
}

\begin{abstract}
To support the raw water development program in the Dam District, there have been many development studies and development programs and rehabilitation programs to meet the needs of the population through the Brantas River Basin Central work unit and PDAM. This region is in dire need of water to improve the welfare of the Trenggalek Regency population, most of whom are living from the farm. And also to meet raw water needs in order to support the pase of regional development and the economy in the surrounding region. Then, analyze population growth for the next 5 years based on Bayong River Springs and raw water network equipment to accommodate the plan. With the availability of bayong river springs, the average discharge per month can be calculated for 5 years. With debit data that reaches 900 liters/sec and population growth for the next 5 years with an average growth of 2\% reaching 32949 people, then with consumption per person 100 liters/sec, the population needs clean water reaches 59 liters/second. To fulfill the need for raw water, so Bendungan District can be relied upon after the Bayong River Springs.
\end{abstract}

Keywords: Debit, River, Raw Water, Population Analysis

\begin{abstract}
Abstrak
Untuk mendukung program pengembangan air baku di wilayah Kec. Bendungan, telah banyak diadakan studi pengembangan dan dilaksanakan program pembangunan maupun rehabilitasi untuk pemenuhan kebutuhan masyarakat melalui Satuan Kerja Balai Besar Wilayah Sungai Brantas dan PDAM setempat. Wilayah ini sangat membutuhkan air untuk meningkatkan kesejahteraan penududuk Kabupaten Trenggalek yang sebagian besar masyarakatnya adalah hidup dari pertanian itu, juga untuk memenuhi kebutuhan air baku agar dapat mendukung laju perkembangan wilayah serta perekonomian di wilayah sekitarnya. Maka menganalisa pertumbuhan penduduk sekarang sampai 5 tahun ke depan berdasarkan mata air Sungai Bayong dan perlengkapan jaringan air baku untuk mengakomodir rencana tersebut. Dengan ketersediaan mata air Sungai Bayong dihitung debit rata-rata per bulan selama 5 tahun. Dengan data debit yang mencapai 900ltr/dtk dan pertumbuhan penduduk 5 tahun kedepan dengan pertumbuhan rata-rata $2 \%$ mencapai 32949 jiwa, maka dengan konsumsi per orang 100 ltr/dtk kebutuhan total air bersih penduduk Kec. Bendungan 59 ltr/dtk. Untuk pemenuhan kebutuhan air baku, maka di Kec. Bendungan dapat diandalkan setelah adanya mata air Sungai Bayong tersebut.
\end{abstract}

Kata Kunci : $\quad$ Debit, Sungai, Air Baku, Analisa Penduduk 


\section{PENDAHULUAN}

Tidak Semua daerah pemukiman mempunyai keberuntungan dalam mendapatkan air baku yang terjamin baik jumlah dan kontinuitasnya guna memenuhi kebutuhan sehari - hari, sementara disuatu daerah ada yang mempunyai potensi air yang berlimpah dan tidak termanfaatkan, [1][2][3]. Disisi lain dengan semakin pesatnya pertambahan penduduk, maka semakin meningkat pula kebutuhan air baku untuk kebutuhan sehari - hari, [4][5][6]. Kecamatan Bendungan Kabupaten Trenggalek. Bendungan adalah sebuah kecamatan yang terletak di bagian utara KabupatenTrenggalek. Wilayahnya yang hampir semuanya pegunungan yang terletak di sebelah selatan Gunung Wilis. Kecamatan Bendungan memiliki luas wilayah sebesar 90,84 Km pada koordinat 7053'-8034' Lintang Selatan dan 111 024' -112 011' Bujur Timur.Secara admnistratif, Kecamatan Bendungan terdiri dari 14 desa, 39 dusun, 114 RW, dan 252 RT dengan jumlah keseluruhan penduduk 35458 jiwa. Kebutuhan air saat ini terpenuhi dengan mengalirkan air melalui selang dan pipa paralon dengan kondisi tidak lancar sehingga harus diatur secara bergilir, untuk itu perlu dipikirkan upaya mendekatkan potensi air kedaerah yang membutuhkan dengan membuat sambungan pipa, [7][8][9].

Sumber Mata Air Sungai Bayong di Desa Ngares Kecamatan Bendungan mempunyai debit air yang sangat besar tetapi penduduk kecamatan bendungan tidak bisa menggunakan Sumber Mata Air Sungai Bayong. Dikarenakan penduduk tidak tahu cara menyalurkan dan tidak mempunyai sarana dan prasarana untuk menyalurkan ke Kecamatan Bendungan, [9][10][11]. Oleh sebab itu, penduduk Kecamatan Bendungan masih kekurangan air untuk memenuhi kebutuhan sehari-hari, [12][13][14]. Sementara itu, penduduk kecamatan bendungan mengambil air dari sumber mata air air. Dengan cara menampung air di Bak Tandon kemudian dikeluarkan melalui selang-selang kecil menuju rumah penduduk. Apabila sumber mata air Sungai Bayong dapat disalurkan ke penduduk Kecamatan Bendungan tentunya akan meciptakan kesejahteraan bagi penduduk dalam hal pemenuhan kebutuhan air [15].

\section{METODE PENELITIAN}

\subsection{Lokasi Penelitian.}

Penelitian ini dilakukan di mata air Sungai Bayong di Kecamatan Bendungan Kabupaten Trenggalek menggunakan metode analisa.

\subsection{Langkah-langkah Penelitian}

Yang pertama yaitu persiapan mulai dari mengurus surat-surat adminitrasi serta menghubungi pihak instansi terkait. Lanjut ke survey lapangan dan studi literatur yang berkaitan 
dengan penelitian ini lalu mengumpulkan data yang ada serta mengidentifikasi masalah. Lanjut ke penelitian dan pengolahan data, dan yang terakhir menyimpulkan dan memberikan saran.

\subsection{Pengukuran debit air dengan Metoda Apung}

Metoda ini menggunakan alat bantu suatu benda ringan (terapung) untuk mengetahui kecepatan air yang diukur dalam satu aliran terbuka,[16][17]. Biasanya dilakukan pada sumber air yang membentuk aliran yang seragam (uniform), [18][19].

Pengukuran dilakukan oleh 3(tiga) orang yang masing- masing bertugas sebagai pelepas pengapung di titik awal, pengamat di titik akhir lintasan dan pencatat waktu perjalanan alat pengapung dari awal sampai titik akhir.

1. Perhitungan Luas Penampang

Tabel 1. Perhitungan Luas Penampang

\begin{tabular}{|l|l|l|c|c|c|}
\hline \multirow{2}{*}{ Titik } & $\begin{array}{c}\text { Lebar (L) } \\
\text { (Meter) }\end{array}$ & \multicolumn{4}{|c|}{$\begin{array}{c}\text { Kedalaman (H) } \\
\text { (Meter) }\end{array}$} \\
\cline { 2 - 6 } & & H1 & H2 & H3 & H rata-rata \\
\hline Titik 1 & & & & & \\
\hline Titik 2 & & & & & \\
\hline Titik 3 & & & & & \\
\hline Titik 4 & & & & & \\
\hline Titik 5 & & & & & \\
\hline Jumlah & & & & Jumlah & \\
\hline $\begin{array}{l}\text { Rata- } \\
\text { rata }\end{array}$ & & & & Rata-rata & \\
\hline
\end{tabular}

Sumber : Analisis data

Luas penampang (A) merupakan hasil perkalian antara Lebar rata-rata (L) saluran/aliran dengan Kedalaman rata-rata $(\mathrm{H})$ saluran/aliran air.

$$
\mathrm{A}=\mathrm{L} \text { rata-rata } \mathrm{x} H \text { rata-rata }
$$

dimana :

A $\quad=$ Luas Penampang $\left(\mathrm{m}^{2}\right)$

$\mathrm{L}$ rata-rata $=$ Lebar rata-rata (meter)

$\mathrm{H}$ rata-rata $=$ Kedalaman rata-rata (meter)

2. Penghitungan Kecepatan (v)

Panjang saluran/lintasan pengukuran $(\mathrm{P})=---$ meter $($ Panjang lintasan harus tetap) 
Tabel 2. Perhitungan Kecepatan

\begin{tabular}{|l|l|}
\hline \multicolumn{1}{|c|}{ Pengulangan } & Waktu Pengukuran (T) (detik) \\
\hline Pengukuran 1 & \\
\hline Pengukuran 2 & \\
\hline Pengukuran 3 & \\
\hline Pengukuran 4 & \\
\hline Pengukuran 5 & \\
\hline Jumlah & \\
\hline Rata-rata & \\
\hline
\end{tabular}

Sumber : Analisis data

Kecepatan (v) adalah hasil pembagian antara panjang saluran/aliran (P) dibagi dengan waktu rata-rata (T rata-rata).

$$
\begin{array}{ll}
\mathrm{V}=\frac{\mathrm{P}}{\text { Trata-rata }} & \\
\text { dimana }: & \\
\mathrm{V} & =\text { Kecepatan (meter/detik) } \\
\mathrm{P} & =\text { Panjang saluran (meter) } \\
\text { T rata-rata } & =\text { Waktu rata-rata (detik) }
\end{array}
$$

3. Penghitungan debit air

Debit air (Q) merupakan hasil perkalian antara luas penampang (A) saluran/aliran dengan kecepatan (v) aliran air.

$$
\mathrm{Q}=\mathrm{A} . \mathrm{V}
$$

dimana:

$\mathrm{Q}=$ Debit aliran (m3/detik)

$\mathrm{A}=$ Luas penampang saluran $\left(\mathrm{m}^{2}\right)$

$\mathrm{V}=$ Kecepatan aliran air (m/detik)

Konversi satuan :

$1 \mathrm{M}^{3}=1000$ Liter

1 Liter $=0,001 \mathrm{M}^{3}$

Contoh : 0,632 $\mathrm{M}^{3} /$ detik $=632 \mathrm{Liter} / \mathrm{detik}$

\subsection{Analisa Proyeksi Jumlah Penduduk}

Jumlah penduduk pada daerah studi pada tahun saat perencanaan dimulai dan pada tahuntahun yang akan datang harus diperhitungkan untuk menghitung kebutuhan tiap penduduk [20]. 


$$
\begin{array}{rlr}
P n & =P o(1+r)^{n} & (\text { Persamaan } 1) \\
P n & =P o(1+r . n)
\end{array}
$$

dengan :

Pn $\quad=$ jumlah penduduk pada tahun ke $\mathrm{n}$ (jiwa)

Po = jumlah penduduk pada awal proyeksi (jiwa)

$\mathrm{r} \quad=$ prosentase pertumbuhan penduduk (\%)

$\mathrm{n} \quad=$ jumlah proyeksi (tahun)

\subsection{Analisa Kebutuhan Air Baku}

Kebutuhan air baku antara kota satu dengan yang lain berbeda-beda,[21]. Faktor-faktor yang mempengaruhi pemakaian air baku, adalah sebagai berikut:

a. Iklim

Di daerah beriklim panas, pemkaian air rata-rata per orang per hari akan lebih banyak dari pada daerah dingin.

b. Karakteristik Penduduk

Tinggi rendahnya tingkat kesejahteraan penduduk dan pola hidup sehari-hari akan mempengaruhi pemakaian air.

c. Keberadaan Industri

Keberadaan industri membutuhkan air untuk produksi sehingga mempengaruhi pemakaian air.

\subsection{Fluktuasi Kebutuhan Air Baku}

1. Kebutuhan air rata-rata, yaitu kebutuhan air rata-rata yang dikonsumsi setiap orang setiap harinya.

2. Kebutuhan air maksimum, yaitu kebutuhan air sebesar dari kebutuhan rata-rata harian dalam satu minggu. Kebutuhan harian maksimum digunakan untuk meghitung kebutuhan kebutuhan air bersih pada pipa transmisi.

3. Kebutuhan air pada jam puncak, yaitu kebutuhan puncak pada jam-jam tertentu dalam satu hari. Kebutuhan air pada jam puncak digunakan untuk menghitung kebutuhan air pada pipa distribusi.

Tabel 3. Kebutuhan Air Bersih

\begin{tabular}{|c|c|}
\hline Kategori Kota & Kebutuhan Air Bersih (lt/orng/hr) \\
\hline Kota Metropolitan & $150-200$ \\
Kota Besar & $120-150$ \\
Kota Sedang & $90-120$ \\
Kota Kecil & $60-90$ \\
\hline
\end{tabular}




\begin{tabular}{|c|c|}
\hline Desa & $40-60$ \\
& \\
\hline
\end{tabular}

Sumber : Dirjen Cipta Karya

\subsection{Jenis-Jenis Cara Penangkapan Air}

1. River Intake

Digunakan untuk menyadap air baku yang berasal dari sungai atau danau.

2. Air baku dari mata air (Spring intake atau broncaptering)

Digunakan untuk mengambil air dari mata air,dalam pengumpulannya, hendaknya dijaga supaya kondisi tanah tidak terganggu.

\subsection{Dasar - Dasar Hidrolika Perpipaan}

$\mathrm{Q}_{1^{-}}=\mathrm{A}_{1 .} \mathrm{v}_{1} \ldots \ldots \ldots \ldots \ldots \ldots \ldots \ldots . . . \ldots \ldots$

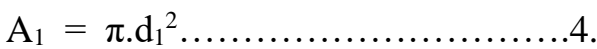

Pers 3. $\rightarrow$ Pers 4 .

$\mathrm{Q}_{1^{-}}=\pi \cdot / 4 \mathrm{~d}_{1^{2}}^{2} \cdot \mathrm{v}_{1}$ .5

dimana :

$\mathrm{v}_{1}=$ kecepatan aliran air pipa di sisi 1 (m/dt)

$\mathrm{A}_{1^{-}}=$Luas penampang pipa di sisi $1 \mathrm{~m}^{2}$

$\mathrm{d}_{1^{-}}=$diameter pipa di sisi $1(\mathrm{~m})$

$\pi$. $=$ konstanta phi atau $22 / 7=3.14$

$\pi . / 4=3.14 / 4=0,785$ atau bila dibulatkan 0.8

Faktor Kehilangan Air Adalah Jumlah Air Yang Hilang Karena Kebocoran, Operasi \& Pemeliharaan Sistem Penyediaan Air, Hidran Kebakaran, gesekan pipa, tikungan atau bend pipa, tinggi rendah elevasi tanah, acesories pipa, Angka Kehilangan Air Yang Dapat Ditoleransi 20\%.

\section{HASIL DAN PEMBAHASAN}

Dalam menganalisa perhitungan debit air rata-rata per bulan :

\subsection{Analisa Debit Air Sumber}

Tabel 4. Analisa Debit Air Sumber

\begin{tabular}{|l|r|r|r|r|r|}
\hline \multirow{3}{*}{ BULAN } & \multicolumn{5}{|c|}{ TAHUN } \\
\cline { 2 - 6 } & 2013 & 2014 & 2015 & 2016 & 2017 \\
\hline
\end{tabular}




\begin{tabular}{|l|r|r|r|r|r|}
\hline JANUARI & 850 & 700 & 900 & 700 & 700 \\
\hline MARET & 850 & 850 & 800 & 850 & 800 \\
\hline APRIL & 700 & 850 & 800 & 850 & 800 \\
\hline MEI & 700 & 850 & 800 & 850 & 650 \\
\hline JUNI & 750 & 850 & 700 & 850 & 650 \\
\hline JULI & 750 & 750 & 700 & 650 & 600 \\
\hline AGUSTUS & 750 & 750 & 700 & 600 & 550 \\
\hline SEPTEMBER & 750 & 750 & 600 & 600 & 550 \\
\hline OKTOBER & 600 & 700 & 600 & 600 & 700 \\
\hline NOPEMBER & 700 & 700 & 600 & 700 & 700 \\
\hline DESEMBER & 700 & 700 & 600 & 700 & 700 \\
\hline
\end{tabular}

Sumber : Analisis Data

\subsection{Analisa Debit Air Sumber Rata-Rata (per Bulan)}

Volume :

Januari $\quad: 770 \mathrm{ltr} / \mathrm{dtk}=0.770 \mathrm{~m} 3 / \mathrm{dtk}$

: $0.770 \times 60 \times 60 \times 24 \times 31=2062368 \mathrm{~m}^{3}$

Februari $\quad: 820 \mathrm{ltr} / \mathrm{dtk}=0.820 \mathrm{~m} 3 / \mathrm{dtk}$

: $0.820 \times 60 \times 60 \times 24 \times 28=1983744 \mathrm{~m}^{3}$

Maret $\quad: 820 \mathrm{ltr} / \mathrm{dtk}=0.820 \mathrm{~m} 3 / \mathrm{dtk}$

: $0.820 \times 60 \times 60 \times 24 \times 31=2196288 \mathrm{~m}^{3}$

April $\quad: 800 \mathrm{ltr} / \mathrm{dtk}=0.800 \mathrm{~m} 3 / \mathrm{dtk}$

: $0.800 \times 60 \times 60 \times 24 \times 30=2073600 \mathrm{~m}^{3}$

Mei $\quad: 770 \mathrm{ltr} / \mathrm{dtk}=0.770 \mathrm{~m} 3 / \mathrm{dtk}$

: $0.770 \times 60 \times 60 \times 24 \times 31=2062368 \mathrm{~m}^{3}$

Juni $\quad: 760 \mathrm{ltr} / \mathrm{dtk}=0.760 \mathrm{~m} 3 / \mathrm{dtk}$

: $0.760 \times 60 \times 60 \times 24 \times 30=1969920 \mathrm{~m}^{3}$

Juli $\quad: 690 \mathrm{ltr} / \mathrm{dtk}=0.690 \mathrm{~m} 3 / \mathrm{dtk}$

: $0.690 \times 60 \times 60 \times 24 \times 31=1848096 \mathrm{~m}^{3}$ 
Agustus $\quad: 670 \mathrm{ltr} / \mathrm{dtk}=0.670 \mathrm{~m} 3 / \mathrm{dtk}$

: $0.670 \times 60 \times 60 \times 24 \times 31=1794528 \mathrm{~m}^{3}$

September $\quad: 650 \mathrm{ltr} / \mathrm{dtk}=0.650 \mathrm{~m} 3 / \mathrm{dtk}$

: $0.650 \times 60 \times 60 \times 24 \times 30=1684800 \mathrm{~m}^{3}$

Oktober $\quad: 640 \mathrm{ltr} / \mathrm{dtk}=0.640 \mathrm{~m} 3 / \mathrm{dtk}$

: $0.640 \times 60 \times 60 \times 24 \times 31=1714176 \mathrm{~m}^{3}$

November $\quad: 680 \mathrm{ltr} / \mathrm{dtk}=0.680 \mathrm{~m} 3 / \mathrm{dtk}$

: $0.680 \times 60 \times 60 \times 24 \times 30=1762560 \mathrm{~m} 3$

Desember $\quad: 680 \mathrm{ltr} / \mathrm{dtk}=0.680 \mathrm{~m} 3 / \mathrm{dtk}$

: $0.680 \times 60 \times 60 \times 24 \times 31=1821312 \mathrm{~m} 3$

3.2 Analisa Pertumbuhan Penduduk dan Kebutuhan Air

\begin{tabular}{|c|c|c|c|c|c|c|c|}
\hline NO & DESA & 2018 & 2019 & 2020 & 2021 & 2022 & 2023 \\
\hline 1 & Bendungan & 2519 & 2569 & 2620 & 2673 & 2762 & 2781 \\
\hline 2 & Gondang & 3048 & 3108 & 3171 & 3234 & 3299 & 3365 \\
\hline 3 & Jarakan & 2389 & 2463 & 2485 & 2535 & 2585 & 2637 \\
\hline 4 & Kiping & 2654 & 2707 & 2761 & 2816 & 2872 & 2930 \\
\hline 5 & Mojoarum & 3356 & 3423 & 3491 & 3561 & 3632 & 3705 \\
\hline 6 & Ngrendeng & 2463 & 2512 & 2562 & 2613 & 2660 & 2719 \\
\hline 7 & Masaran & 2305 & 2351 & 2398 & 2440 & 2495 & 2941 \\
\hline 8 & Sengon & 1188 & 1211 & 1235 & 1260 & 1285 & 1311 \\
\hline 9 & Sumurup & 1777 & 1812 & 1848 & 1885 & 1923 & 2267 \\
\hline 10 & Srabah & 1376 & 1400 & 1431 & 1460 & 1489 & 1519 \\
\hline 11 & Depok & 1780 & 1815 & 1851 & 1888 & 1926 & 1965 \\
\hline 12 & Suren Lor & 1554 & 1585 & 1616 & 1649 & 1682 & 1715 \\
\hline 13 & Dompyong & 1783 & 1818 & 1855 & 1892 & 1929 & 1968 \\
\hline 14 & Botoputih & 3293 & 3358 & 3426 & 3494 & 3564 & 3635 \\
\hline & JUMLAH & 31485 & 32132 & 32750 & 33400 & 34103 & 35458 \\
\hline
\end{tabular}

Sumber : Analisis Data

1. Bendungan 


\section{Sumber : Analisis Data}

Perhitungan proyeksi penduduk

Kebutuhan Air Bersih

Qmd $\quad=$ Pn $\times$ q $\times$ Fmd

$$
\begin{aligned}
& =2781 \times 100 \times 1,15 \\
& =319815 \mathrm{ltr} / \mathrm{hri} \\
& =3,70 \mathrm{ltr} / \mathrm{dtk}
\end{aligned}
$$

2. Kebutuhan air kec. Bendungan

$$
\begin{aligned}
\text { Qmd } & =\text { Pn } \times \text { q } \times \text { Fmd } \\
& =35458 \times 100 \times 1.15 \\
& =4077670 \mathrm{ltt} / \mathrm{hr} \\
& =4077670 / 86400 \\
& =47.20 \mathrm{ltr} / \mathrm{dtk}
\end{aligned}
$$

\begin{tabular}{|c|l|l|l|}
\hline No & \multicolumn{1}{|c|}{ Tahun } & \multicolumn{1}{|c|}{$\mathrm{P}_{0}(1+\mathrm{r})^{\mathrm{n}}$} & \multicolumn{1}{c|}{$\mathrm{P}_{\mathrm{n}}$} \\
\hline 1 & $2018-2019$ & $2519(1+0,02)^{1}$ & 2569 \\
\hline 2 & $2019-2020$ & $2519(1+0,02)^{2}$ & 2620 \\
\hline 3 & $2020-2021$ & $2519(1+0,02)^{3}$ & 2673 \\
\hline 4 & $2021-2022$ & $2519(1+0,02)^{4}$ & 2762 \\
\hline 5 & $2022-2023$ & $2519(1+0,02)^{5}$ & 2781 \\
\hline
\end{tabular}

3. Kebutuhan total air bersih

Qt = Qmd $\times 100 / 80$ (faktor kehilangan air 20\%)

$$
=47.20 \times 100 / 80
$$$$
=59 \mathrm{ltr} / \mathrm{dtk}
$$

\subsection{Kontrol}

Q $=800$ ltr/detik = debit mata air Sungai Bayong $>\mathrm{Q}=59 \mathrm{ltr} / \mathrm{dtk}=$ debit kebutuhan total air baku penduduk Kecamatan Bendungan.

\subsection{Perhitungan kecepatan aliran penangkap air}

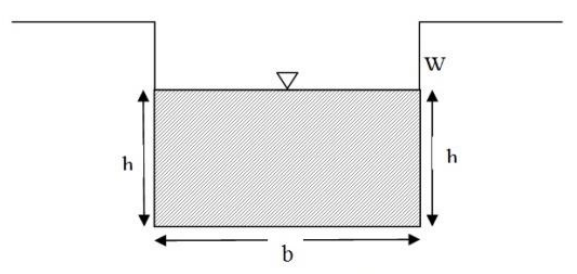


$\mathrm{Q}=100 \mathrm{ltr} / \mathrm{detik}=0,1 \mathrm{~m}^{3} / \mathrm{detik}$

$\mathrm{Q}=\mathrm{A} \times \mathrm{V}----\rightarrow \mathrm{V}=\frac{Q}{A}$

$\mathrm{V}=\frac{0,10}{0,5 \times h}$

$\mathrm{V}=\frac{1}{n} \times \mathrm{R}^{2 / 3} \times \mathrm{I}^{1 / 2}$

$=\frac{1}{0,025} \times\left(\frac{0,5 \times h}{0,5+2 h}\right)^{2 / 3} \times(0,008)^{1 / 2}$

$=40 \times\left(\frac{0,5 \times h}{0,5+2 h}\right)^{2 / 3} \times(0,09)$

$=3,6 \times\left(\frac{0,5 \times h}{0,5+2 h}\right)^{2 / 3}$.

…........ $6=\ldots \ldots \ldots \ldots \ldots \ldots . . .7$

$\frac{0,10}{0,5 x h}=3,6 \times\left(\frac{0,5 \times h}{0,5+2 h}\right)^{2 / 3}$

Dengan coba-coba -- $\rightarrow h$ akan ketemu

$$
\begin{aligned}
\mathrm{V} \quad=\frac{0,10}{0,5 \times 0,25} & =3,6 \times\left(\frac{0,5 \times 0,25}{0,5+2 \times 0,25}\right)^{2 / 3} \\
=0,8 \mathrm{~m} / \text { detik } & =3,6 \times\left(\frac{0,125}{1}\right)^{2 / 3} \\
& =3,6 \times 0,125^{0,67} \\
& =0,8 \mathrm{~m} / \text { detik }
\end{aligned}
$$

Dengan coba-coba $h$ ketemu persamaan $(0,25 \mathrm{~m})$

Dan V ketemu persamaan $(0,8 \mathrm{~m} /$ detik $)$

Tinggi Jagaan

$$
\begin{aligned}
\mathrm{W} & =\sqrt{0,5 \times h} \\
& =\sqrt{0,5 \times 0,25} \\
& =\sqrt{0,125} \\
& =0,35 \mathrm{~m}
\end{aligned}
$$

Kontrol

$$
\begin{array}{ll}
\text { Q hitung } & =\mathrm{A} X \mathrm{~V} \\
& =0,125 \mathrm{~m}^{2} \times 0,8 \mathrm{~m} / \text { detik } \\
& =0,1 \mathrm{~m}^{3} / \text { detik } \\
\text { Q hitung } & =\text { Q rencana } \\
0,1 \mathrm{~m}^{3 / \text { detik }} & =0,1 \mathrm{~m}^{3 / \text { detik }}
\end{array}
$$




\subsection{Perhitungan besar pipa}

Merencanakan dan menghitung besar pipa berdasarkan $\mathrm{V}$ debit penangkap air dan kapasitas air baku yang dibutuhkan oleh penduduk.

$\begin{array}{ll}\mathrm{Q} & =\mathrm{A} \times \mathrm{V} \\ \mathrm{V} & =\underline{\mathrm{Q}}\end{array}$

A

3.6 Penggunaan pipa induk dari Outlet penangkap air menggunakan pipa Ø 10”

1. Pipa Ø $10 "=10 \times 2,5=25 \mathrm{~cm}=0,25 \mathrm{~m}$

$$
\begin{aligned}
& \text { V } \quad \frac{0,1}{\pi \times R^{2}} \\
& =\frac{0,1}{3,14 \times 0,125^{2}} \\
& =\frac{0,1}{3,14 \times 0,015} \\
& =\frac{0,1}{0,0471} \\
& =2,1 \mathrm{~m} / \text { detik }
\end{aligned}
$$

2. Bila diameter pipa $12 " \times 2,5=30 \mathrm{~cm}=0,3 \mathrm{~m}$

$$
\begin{aligned}
& \mathrm{V} \quad=\frac{Q}{A}=\frac{Q}{\pi r^{2}} \\
& =\frac{0,1 \mathrm{~m}^{3} / d t k}{3,14 x(0,15)^{2} \mathrm{~m}^{2}} \\
& =\frac{0,1 \mathrm{~m}^{3} / \mathrm{dtk}}{0,707 \mathrm{~m}^{2}} \\
& =1,4 \mathrm{~m} / \mathrm{dtk}
\end{aligned}
$$

Pipa Ø 10" disini terjadi pengurangan tekanan karena melewati bak pelepas tekan (BPT) menjadi $0,080 \mathrm{~m}^{3} / \mathrm{dtk}$

3. Bila diameter pipa $10 " \times 2,5=25 \mathrm{~cm}=0,25 \mathrm{~m}$

$$
\begin{aligned}
\mathrm{V} & =\frac{Q}{A}=\frac{Q}{\pi r^{2}} \\
& =\frac{0,080 \mathrm{~m}^{3} / \mathrm{dtk}}{3,14 \times(0,125)^{2} \mathrm{~m}^{2}}
\end{aligned}
$$




$$
\begin{aligned}
& =\frac{0,080 \mathrm{~m}^{3} / d t k}{0,047 \mathrm{~m}^{2}} \\
& =1,7 \mathrm{~m} / \mathrm{dtk}
\end{aligned}
$$

\section{KESIMPULAN}

1. Jadi kebutuhan air baku untuk masyarakat Kec. Bendungan yang menggunakan air dari Sungai Bayong sebanyak (35458 jiwa ) adalah sebesar 59 ltr/dtk. Dari ketersediaan mata air Sungai Bayong dapat dimanfaatkan dan layak bagi kelangsungan hidup penduduk Kec. Bendungan

2. Dengan adanya sumber dari Sungai Bayong didukung debit yang sangat besar mencapai 900 ltr/dtk sangat bermanfaat untuk di gunakan menjadi air baku.

3. Jadi debit air yang dibutuhkan penduduk kecamatan Bendungan adalah sebesar 59 ltr/dtk. Dengan Analisa perhitungan sampai 5 tahun ke depan, mata air sungai bayong sangat cukup untuk mencukupi semua kebutuhan air baku penduduk kec. Bendungan.

\section{SARAN}

Sebaiknya di adakan pengkajian lebih dalam tentang analisa kebutuhan air baku bagi penduduk kecamatan Bendungan kabupaten Trenggalek serta pemanfaatan aliran sungai Bayong untuk kebutuhan yang lain.

\section{UCAPAN TERIMAKASIH}

Dalam penyusunan artikel ini, penulis ucapkan terimakasih kepada dosen pembimbing dan Universitas Kadiri. Penulis berharap agar artikel ini dapat bermanfaat bagi pembaca.

\section{DAFTAR PUSTAKA}

[1] D. C. Karya, "Buku Panduan Pengembangan Air Minum," Program, no. 20, 2007.

[2] Pekerjaan Umum (Public Works), "Penyelenggaraan pengembangan sistem penyediaan air minum," 2007.

[3] B. D. M. Amalia Intan Sari, "Perencanaan Peningkatan Sistem Distribusi Air Minum Sumber Mata Air Umbulan di Wilayah Pelayanan Offtake Waru Kabupaten Sidoarjo,” J. Tek. Pomits, vol. 2, no. 1, pp. 10-13, 2013.

[4] E. B. Sasongko, E. Widyastuti, and R. E. Priyono, "Kajian Kualitas Air Dan Penggunaan Sumur Gali Oleh Masyarakat Di Sekitar Sungai Kaliyasa Kabupaten Cilacap," J. Ilmu 
Lingkung., vol. 12, no. 2, p. 72, 2014, doi: 10.14710/jil.12.2.72-82.

[5] G. Nur Afrina, Y. Sri Sundari, and A. Nur, "Evaluasi Kapasitas Daya Tampung Saluran Drainase Jalan A.W Syahranie Pada Kota SAMARINDA,” vol. 105, no. 3, pp. 129-133, 1945.

[6] A. Susanto, Y. C. S. P, and S. Winarto, "STUDI PERENCANAAN JEMBATAN CUMPLENG DENGAN METODE PRATEKAN DI KEC. SLAHUNG KABUPATEN PONOROGO,” Jurmateks, vol. 1, no. 2, pp. 172-181, 2018.

[7] B. Sulistiono, "Evaluasi Kapasitas Saluran Drainase Desa Sariharjo," J. Eval. Kapasitas Saluran Drainse, vol. 14, no. 1, pp. 47-52, 2016.

[8] R. Hidayah, A. Ridwan, and Y. C. S. P, "ANALISA PERBANDINGAN MANAJEMEN WAKTU ANTARA PERENCANAAN DAN PELAKSANAAN,” Jurmateks, vol. 1, no. 2, pp. 281-290, 2018.

[9] S. N. T. S. D. A. 2015, "PENGELOLAAN TERPADU UNTUK MENDUKUNG KETAHANAN AIR BERKELANJUTAN DI KAWASAN PERKOTAAN,” Society.

[10] G. Markovic and M. Zelenakova, "Measurement and evaluation of percolation drainage systems capacity in real conditions," IOP Conf. Ser. Earth Environ. Sci., vol. 92, no. 1, 2017, doi: 10.1088/1755-1315/92/1/012040.

[11] R. Saputo and S. Suprayogi, "Evaluasi Kapasitas Saluran Drainase Perkotaan ( studi kasus: Daerah Tangkapan Air Klitren, Gondokusuman, Yogyakarta )," J. Chem. Inf. Model., vol. 53, no. 9, pp. 1689-1699, 2013, doi: 10.1017/CBO9781107415324.004.

[12] B. Andana, D. Arisanty, S. Adyatma, and I. Pendahuluan, "Evaluasi daya tampung sistem drainase di kecamatan banjarmasin selatan," JPG (Jurnal Pendidik. Geogr., vol. 3, no. 4, pp. 1-13, 2016.

[13] W. T. Cahyono, Y. C. SP, and S. Winarto, "STUDI EFISIENSI PEMBERIAN AIR IRIGASI PADA DESA GROMPOL, KECAMATAN GAMPENGREJO, KABUPATEN KEDIRI,” Jurmateks, vol. 1, no. 1, pp. 12-21, 2018.

[14] R. Tamimi, S. Wahyuni, and E. Hidayah, "Kajian Evaluasi Sistem Drainase Jalan Srikoyo Kecamatan Petrang Kabupaten Jember,” Rekayasa Sipil, vol. 10, no. 2, pp. 106-113, 2016.

[15] A. I. Candra and E. Siswanto, "Rekayasa Job Mix Beton Ringan Menggunakan Hydroton Dan Master Ease 5010,” J. CIVILA, vol. 3, no. 2, p. 162, 2018, doi: 10.30736/cvl.v3i2.258.

[16] R. Febrianto et al., "Studi evaluasi jaringan drainase rawa kepah di wilayah banjir kanal barat provinsi dki jakarta."

[17] A. Sarminingsih, "Drainage System Evaluation as An Effort to Reduce Flood Inundation in Gedebage Area, Bandung - West Java," IOP Conf. Ser. Earth Environ. Sci., vol. 366, no. 1, 2019, doi: 10.1088/1755-1315/366/1/012035. 
[18] P. R. M. Norman, "Evaluasi Kapasitas Saluran Drainase UNESA Dengan Adanya Pengembangan Kawasan Surabaya Barat,” 2017.

[19] I. K. Sari, L. M. Limantara, and D. Priyantoro, "Analisa Ketersediaan dan Kebutuhan Air pada DAS Sampean,” J. Tek. Pengair., vol. 2, no. 1, pp. 29-41, 2012.

[20] J. Sutikno, A. Ridwan, and Y. C. SP, "ANALISA STABILITAS CHECKDAM PABYONGAN DESA MULYOSARI KECAMATAN PAGERWOJO KABUPATEN TULUNGAGUNG," Jurmateks, vol. 1, no. 1, pp. 66-75, 2018.

[21] Suroso, A. Suharyanto, M. Ruslin Anwar, Pudyono, and D. H. Wicaksono, "Evaluasi dan perencanaan ulang saluran drainase pada kawasan perumahan sawojajar kecamatan kedungkandang kota malang," vol. 8, no. 3, pp. 207-213, 2014. 